\title{
A WORD FROM THE PUBLISHER
}

\section{The scientific process: new forces attempt to enter the scene}

\author{
Otto Kinne* \\ Inter-Research, Nordbünte 23, 21385 Oldendorf/Luhe, Germany
}

For more than 4 decades editorial responsibilities and the direction of scientific journals have made up a considerable, and still growing, part of my professional life. I have followed with great interest the increasingly important role of editors and referees and the development and status of scientific journals. And I have published several articles presenting my pertinent experiences and views.

Authors, editors and reviewers are the heart of science. Authors produce and present new scientific information. Editors and reviewers (internationally acknowledged experts in defined fields of research and authors of scientific articles themselves) critically evaluate the information presented, making judgements on the basis of methods and principles of scientific research developed over many decades and endorsed by the scientific community. The peer review system 'has been used almost universally in relatively unchanged form ever since about 1750' (Day 1998, p 122). Its primary aim is to evaluate the procedures adopted for producing new research results and their interpretations, and to assist in quality improvement.

Editors select reviewers, study their reports and, after making their own assessment of the methods, results and conclusions presented, as well as the relevance of the manuscript's topic to the journal's scope, decide on the future of the manuscript. This is the essence of the scientific process which I dealt with in more detail in a previous publication (Kinne 1988).

The scientific process can function adequately only if the editor is free in her/his decision, impartial, fair and focussed on scientific quality. An editor should be as helpful as possible to young, inexperienced authors and should be courageous enough to accept scientifically sound work that challenges 'holy cows'. Such challenges, and the subsequent discussions that usually follow, are the salt and pepper of science - important stimuli for new thoughts and concepts.

The growing influence of science on human societies and their multiple activities has recently caused forces to enter the scene that are not part of the scientific process in its original sense; forces that are primarily fuelled not by scientific fact or argument but by political or economical interests. These forces must not be allowed to compromise or distort established and proven methods of 'truth finding'. We cannot have lobbyists and pressure groups in science! If someone wishes to criticise a published paper s/he must present facts and arguments and give criticised parties a chance to defend their position.

Inter-Research journals offer an opportunity for fair intellectual exchanges in the form of Comments and Reply Comments. Comments are critical re-assessments of published works and Reply Comments are answers by the authors criticised. Such direct post-publication critique (Kinne 2002) has been employed by an increasing number of scientists and has served the scientific process well.

\section{LITERATURE CITED}

Day RA (1998) How to write \& publish a scientific paper, 5th edn. Oryx, Phoenix, AZ

Kinne O (1988) The scientific process - its links, functions and problems. Naturwissenschaften 75:275-279

Kinne O (2002) Importance and organisation of direct postpublication critique. Mar Ecol Prog Ser 228:1

This text is also to be published in Marine Ecology Progress Series, Aquatic Microbial Ecology, Diseases of Aquatic

Organisms, Climate Research 